\title{
EXEQUATUR, NULIDAD DE ACTUACIONES \\ E INDEFENSIÓN... Y OTRAS CUESTIONES NO MENOS \\ RELEVANTES (AUTO DE LA AUDIENCIA PROVINCIAL \\ DE BARCELONA DE 18 DE MAYO DE 2020)
}

\section{EXEQUATUR, NULLITY OF PROCEEDINGS, LACK OF LEGAL DEFENSE... AND OTHER ISSUES NOT LESS IMPORTANT (ORDER OF THE PROVINCIAL COURT, MAY 18TH, 2020)}

\author{
Maria del Ángel IGLESIAS \\ Profesora de Derecho Internacional y de la Unión Europea \\ UNIR, Universidad Internacional de La Rioja \\ ORCID ID: 0000-0002-3069-0183
}

Recibido: 19.11.2020 / Aceptado: 04.12.2020

DOI:https://doi.org/10.20318/cdt.2021.6002

\begin{abstract}
Resumen: El presente comentario versa sobre el Auto de la Audiencia Provincial de Barcelona de 18 de mayo de 2020 que, a priori, no parecería tener mayor interés si tomamos como referencia los descriptores de la decisión. Sin embargo, merece la pena detenerse en el análisis de determinadas referencias que el Auto contiene, como las efectuadas respecto de la jurisdicción voluntaria, del pacto al que puede llegarse en el marco de un procedimiento contencioso y respecto de éste mismo. Ello, junto a lo que constituye el núcleo de la decisión: la validez en España de una decisión tomada en Ecuador relativa a alimentos de menores y la alegada nulidad de actuaciones, junto a la vulneración de uno de los derechos esenciales del debido proceso, al no haberse dado traslado debido de la demanda a la contraparte.

Palabras clave: derecho de defensa, exequatur, jurisdicción voluntaria, nulidad de actuaciones, transacción judicial.
\end{abstract}

Abstract: The present commentary deals with the Order of the Provincial Court of Barcelona of May 18, 2020 which, a priori, would not seem to be of much interest if we take the descriptors of the decision as a reference. However, it is worthwhile to analyse some references contained in the Order, such as those made with respect to voluntary jurisdiction, the arrangement that may be reached in the scope of a contentious procedure, and to the latter itself. All of this, together with what constitutes the core of the decision: the validity in Spain of a decision taken in Ecuador concerning child support, the alleged nullity of proceedings together with the violation of one of the essential rights of due process by not having given due notice of the lawsuit to the other party.

Keywords: right of defence, exequatur, voluntary jurisdiction, nullity of proceedings, judicial settlement.

Sumario: I. Antecedentes de Hecho. II. Cuestiones a analizar: el derecho a aplicar al exequatur. 1. Jurisdicción Voluntaria y Transacciones Judiciales. III. El derecho de defensa y la nulidad de actuaciones. IV. Observaciones finales.

* Roj: AAP B 3212/2020 - ECLI: ES: APB:2020: 3212ª Id Cendoj: 08019370182020200124. 


\section{Antecedentes de hecho}

1. En un proceso de alimentos llevado a cabo en Ecuador, las partes llegaron a un acuerdo, con fecha 7 de marzo de 2018, por el cual el padre se obligaba a pagar una determinada cantidad de dinero en favor de las hijas del matrimonio. ${ }^{1}$

Este acuerdo fue aprobado ante la instancia judicial ecuatoriana correspondiente dos días después, el 9 de marzo de 2018.

Se presentó, en España, exequatur de este acuerdo el día 2 de agosto de 2018, sin que el Ministerio Fiscal se opusiese y respecto del cual recayó Auto, con fecha 26 de julio de 2019, en el que se procede a su reconocimiento y ejecución.

2. Tal Auto se recurrió en apelación en nuestro país. La base jurídica en la que la instancia española se basó, para dar reconocimiento a la decisión mencionada y que constan en el Auto recurrido de 26 de julio de 2019 fue: el artículos 44 de la Ley de Cooperación Jurídica Internacional ("reconocimiento") y el artículo 399 de la Ley de Enjuiciamiento Civil ("de la demanda y su contenido").

Es importante señalar que no se recurre la obligación acordada de pagar alimentos.

3. El acuerdo al que llegaron en el país de origen se halla en fase de ejecución y en la misma existen divergencias entre las partes, si bien no en cuanto al fondo (cantidad de dinero a la que el padre se obligó a dar a sus hijas), sino en cuanto a las circunstancias en se produce el pago ya que "las ayudas familiares las pasó a cobrar ella de la empresa porque el padre no las aplicó al pago de colegios y vivienda" ${ }^{2}$. Es importante, además, tener en cuenta que se presentó resolución ecuatoriana de fecha 6 de enero de 2020 por la que se revoca la decisión de 9 de marzo de 2018 declarando la extinción de alimentos a partir del 19 de marzo de 2019, fecha de la sentencia del juzgado de Primera Instancia 16 de Barcelona que recayó en regulación de medidas.

4. Se llevan pues a cabo una serie de procedimientos en España y en Ecuador que podemos sintetizar de la siguiente forma:

1.1. Actuaciones en Ecuador: a) pleito de alimentos con acuerdo de 9 de marzo de 2018; b) posterior recurso que extingue la obligación de pago desde la misma fecha que el Juzgado de Barcelona (19 de marzo de 2019).

1.2. Actuaciones en España: a) exequatur del acuerdo de conciliación (2 de agosto de 2018) respecto del pago de alimentos y b) modificación de medidas ante el Juzgado de Primera Instancia 16 de Barcelona (decisión de 19 de marzo de 2019) extinguiéndose la obligación de pago de alimentos.

5. En el recurso de apelación contra la decisión española que admite el exequatur del acuerdo al que llegaron los litigantes en marzo de 2018, el recurrente solicita nulidad de actuaciones, al no habérsele dado traslado de la demanda, (lo que implica indefensión).

Es de resaltar que el Ministerio Fiscal no se opone a la nulidad que invoca la parte apelante en esta etapa del proceso. La base jurídica en que se apoya el apelante es el artículo 54.5 de la LCJI ("proceso" de exequatur).

La parte apelada alega, de contrario, que "en proceso de mutuo acuerdo no es preciso dar traslado de la demanda (el recurrente fue el demandado en el juicio de origen y cita la STS de 23 de septiembre de 2003 y la doctrina de los actos propios)". Además, alega el conocimiento del recurrente del proceso de exequatur "en razón de la contestación a la demanda de regulación de medidas presentada de contrario en el Juzgado n.16 de Barcelona (donde la apelada alegó litispendencia)"’. En consecuencia, en procedimiento de regulación de medidas.

\footnotetext{
${ }^{1}$ Juicio 17203201710847.

${ }^{2}$ Cfr. para 2 de los Antecedentes de Hecho.

${ }^{3}$ Cfr. para 2 de los Antecedentes de Hecho.
} 


\section{Cuestiones a analizar: el derecho a aplicar al exequatur}

6. Después de un recorrido por las normas a aplicar en defecto de Convenio internacional o del Derecho de la Unión Europea (UE), el Auto establece correctamente que es el ordenamiento jurídico español el que debe aplicarse, en concreto el Título V de la Ley 29/2015, de 30 de julio, de cooperación jurídica internacional en materia civil, que regula el procedimiento de reconocimiento y también el de ejecución de sentencias extranjeras (artículos 41 y ss.).

En efecto, y siguiendo las fuentes de producción del derecho internacional (privado, en este supuesto), no existe convenio entre la República del Ecuador y España. Son muchos los acuerdos que nuestro país ha suscrito con diferentes estados relativos a cooperación en materia civil -generales o específicos- que incluyen disposiciones relativas al reconocimiento y ejecución de sentencias extranjeras ${ }^{4}$. A falta de convenio aplicable, es el Derecho de la UE el llamado a ser aplicado, pero nos encontramos, aquí, con el obstáculo derivado de que estamos ante un Estado que no es parte de la UE. Así pues, acudimos a las normas de producción interna.

Tal y como consta en el Auto, en principio, el procedimiento aplicable a este procedimiento es el previsto en el artículo 54 de la Ley de Cooperación Jurídica Internacional. Hasta ahí no hay cuestión alguna a señalar, pero conviene recordar y resaltar su punto 5: ello, porque este precepto establece que se ha de dar traslado "a la parte demandada para que se oponga en el plazo de treinta días" y porque seguidamente la Audiencia establece -como aplicable- una excepción a esta regla general sobre el conocimiento de la contraparte.

7. En efecto, dice el Auto: "el art. 41.2 permite el reconocimiento de las resoluciones extranjeras definitivas adoptadas en el marco de un procedimiento de jurisdicción voluntaria y, ciertamente, el reconocimiento que aquí se insta se corresponde con una resolución judicial que, en trámite de conciliación, acepta el acuerdo voluntario alcanzado por los litigantes, en un proceso en el que el Sr. Doroteo fue parte y asintió al acuerdo. El art. 51 dice que las transacciones judiciales (como es el caso) se ejecutarán conforme a las anteriores previsiones". Ello, para afirmar que "sólo en los procedimientos contenciosos el demandado era emplazado", entendiendo que ello no aplica cuando se trata de un procedimiento de mutuo acuerdo.

8. Nótese que en un solo párrafo se hace alusión a la jurisdicción voluntaria, al pacto al que las partes puedan llegar en el curso de un procedimiento contencioso y a la transacción judicial, pero, con respecto al primer punto, la alusión a la jurisdicción voluntaria creemos, con todo respeto, que la Audiencia yerra. Por más que se haya llegado a un acuerdo entre las partes, no puede afirmarse que estemos ante un procedimiento de Jurisdicción Voluntaria.

\section{Jurisdicción Voluntaria y Transacciones Judiciales}

9. El artículo 1 de la Ley de Jurisdicción Voluntaria de 2015 reza en su punto 2 que "se consideran expedientes de jurisdicción voluntaria, a los efectos de esta Ley, todos aquellos que requieran la intervención de un órgano jurisdiccional para la tutela de derechos e intereses en materia de Derecho civil y mercantil, sin que exista controversia que deba sustanciarse en un proceso contencioso.”. Es una característica propia de estos actos, la ausencia de contradicción y la consecuencia derivada de ello: la del no producir efecto de cosa juzgada. En el caso presente existen demandante y demandado que llegan a un acuerdo en el curso de un procedimiento contencioso como el propio Auto señala y sin que se haga referencia posterior a artículo alguno de esta ley para llegar a su decisión final y para hablar seguidamente de transacción judicial.

10. Conviene traer a colación los requisitos exigidos en la normativa española para que los actos de jurisdicción voluntaria surtan efectos en España. Y así, siguiendo a Calvo Caravaca y Carras-

\footnotetext{
${ }^{4}$ Una lista de los convenios existentes puede encontrarse en a.l. Calvo Caravaca J. Carrascosa González. Derecho Internacional Privado. Vol. I. 16 ${ }^{a}$. Ed. Comares, 2016. p. 752.
} 
cosa González ${ }^{5}$ deben ser: a) firmes o definitivos, que ya no puedan modificarse por las autoridades extranjeras competentes en el sector de la jurisdicción voluntaria, b) deben superar el reconocimiento, cabiendo el reconocimiento incidental y, c) deben acreditar su autenticidad. Entre los motivos por lo que procedería su denegación se halla el de que "el acto hubiera sido acordado con manifiesta infracción de

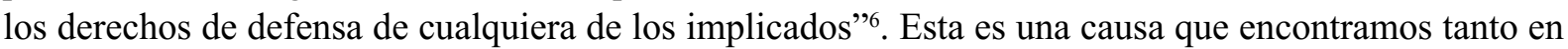
el derecho internacional privado de la Unión Europea, como en los convenios internacionales, como en el derecho interno español, al tratarse de una garantía de los derechos más básicos de defensa y a lo que haremos después referencia puntual.

11. Respecto a la transacción judicial -mencionada, como ya hemos dicho en el Auto- el artículo 49 de la LCJI nos proporciona como concepto el siguiente: "todo acuerdo aprobado por un órgano jurisdiccional de un Estado o concluido ante un órgano jurisdiccional de un Estado en el curso del procedimiento", pero acertadamente señalan Calvo-Caravaca y Carrascosa González "no es una decisión judicial, ni siquiera de jurisdicción voluntaria ${ }^{7}$... Se caracterizan por su efecto ejecutivo, no es firme ni produce el efecto de cosa juzgada" 8 .

Nuestro Tribunal Supremo, en sentencia de 5 de abril de $2010^{9}$ indicó que "la imposibilidad de replantear las cuestiones transigidas no implica que la transacción sea invulnerable, ya que puede impugnarse su validez y eficacia, dejándola sin efecto y reavivando la situación jurídica anterior".

Admitiendo que hubiera transacción judicial, la LCJI -como dice el Auto- establece para aque1la, las mismas disposiciones que para el exequatur, digamos que un procedimiento "resuelto de mutuo acuerdo", pero, sin embargo, hemos de señalar que no pierde la naturaleza contenciosa en que ha nacido ni queda equiparado a la jurisdicción voluntaria.

12. Una transacción judicial, para ser reconocida en España, tendría que superar el exequatur previamente. Y nos encontramos en el presente caso, con que difícilmente podría superarse sino parcialmente, al haberse apelado en Ecuador. Sostiene Gascón Inchausti ${ }^{10}$ que "El único límite a su reconocimiento lo establece el artículo 46.2 LCJIC y es la contrariedad con el orden público -sin que, por tanto, se apliquen las demás causas del artículo 46.1. Afirman Calvo Caravaca y Carrascosa González ${ }^{11}$ que este artículo es "parco en palabras y dudoso en intenciones,". Por ello, entienden precisa su interpretación conforme a la normativa en que se inspiró ${ }^{12}$ ", por lo que, de igual forma, sostienen que la contrariedad al orden público es la única causa para su denegación.”.

13. Según el Auto (punto 2 párrafo 1): "El art. 41.2 permite el reconocimiento de las resoluciones extranjeras definitivas adoptadas en el marco de un procedimiento de jurisdicción voluntaria ${ }^{13}$ $\mathrm{y}$, ciertamente, el reconocimiento que aquí se insta se corresponde con una resolución judicial que en trámite de conciliación acepta el acuerdo voluntario alcanzado por los litigantes, en un proceso en el que el Sr. Doroteo fue parte y asintió al acuerdo. El art. 51 dice que las transacciones judiciales (como es el caso) se ejecutarán conforme a las anteriores previsiones" (...) "En suma, entendemos que sólo es exigible la audiencia y contradicción cuando se trate de procedimiento contencioso, pero no para el procedimiento resuelto de mutuo acuerdo. Si el legislador hubiera querido imponer en todo caso la previa audiencia de la parte contraria debería haberlo dicho expresamente.".

\footnotetext{
${ }^{5}$ A.L. Calvo Caravaca J. Carrascosa GonZÁlez, ob.cit p. 825.

${ }^{6}$ A.L. Calvo Caravaca J. Carrascosa GonzÁlez, ob.cit. p. 826.

${ }^{7}$ El resaltado es mío.

${ }^{8}$ a.L. Calvo Caravaca J. Carrascosa GonzÁlez, ob.cit. p. 829.

${ }^{9}$ Sala de lo Civil, ST de 5 de abril de 2010, Rec. 2371/2005 (La Ley, 27010/2010).

${ }^{10}$ F. Gascón Inchausti, "Reconocimiento y Ejecución de Resoluciones Judiciales Extranjeras en la Ley de Cooperación Jurídica Internacional en materia Civil.”. Cuadernos de Derecho Transnacional (octubre 2015), Vol. 7, № 2, pp. 158-187, p. 184.

${ }^{11}$ a.L. Calvo Caravaca J. Carrascosa González, ob.cit. p. 829.

${ }^{12}$ Reglamento 1215/2012, artículos 58 y 59.

${ }^{13}$ En este sentido discrepamos ya que como se ha dicho, no puede hablarse en este caso de Jurisdicción Voluntaria y dicho sea con el debido respecto, la redacción aquí es confusa y parece equiparar a aquellas con las transacciones judiciales.
} 
14. Según se desprende del Auto, el acuerdo alcanzado en primera instancia es objeto de contestación por parte del demandado. Este extremo es importante y pone de manifiesto la ruptura del acuerdo alcanzado. La relevancia viene dada porque se considera un pleito independiente, con lo cual, no tiene en cuenta el estado de la cuestión estrechando el cerco del asunto al del reconocimiento del acto transaccional alcanzado en un determinado momento. "La resolución aportada en este Rollo del Tribunal de Quito resolviendo recurso de apelación, no está dictada en el proceso del que nace la resolución cuyo exequátur se insta, sino de un proceso de ejecución por impago de pensiones". Sin embargo, consta en el mismo que extinguió los alimentos, por lo que entendemos que guarda estrecha relación: en el apartado 3 de los Antecedentes de Hecho (Trámites en Sala) consta que el Tribunal ecuatoriano revocó el auto de la jueza en el mismo juicio que fue objeto de exequatur declarando la extinción de alimentos ${ }^{14}$.

15. Retrocedamos por un momento y plantémonos: resuelto un asunto de mutuo acuerdo, ¿queda este fuera de la norma general de dar traslado al demandado? Se argumenta, de contrario, que el hecho de que conociera el demandado su existencia (por vía diferente a la de este procedimiento) libera de la obligación de dar traslado. No podemos estar de acuerdo con esta apreciación ya que no hay norma alguna en nuestro ordenamiento en tal sentido y sería peligroso para la seguridad jurídica el aplicar este modo de dar por cumplido el trámite de traslado de la demanda.

16. El Auto, recuerda "Solo en los procesos contenciosos el demandado era emplazado" (refiriéndose a la antigua LEC de 1881) y continua: "entendemos que sólo es exigible la audiencia y contradicción cuando se trate de procedimiento contencioso, pero no para el procedimiento resuelto de mutuo acuerdo. Si el legislador hubiera querido imponer en todo caso la previa audiencia de la parte contraria debería haberlo dicho expresamente" "No hay tampoco infracción del derecho de defensa (art. 46.1 b) porque el recurrente participó y asintió a la conciliación en el país de origen.”

17. Entendemos que la apelada trató y trata de dar eficacia en España a una resolución que, en efecto, fue acordada en el marco de un procedimiento contencioso que así ha vuelto a devenir posteriormente. Ello, nos parece fundamental para establecer los límites o las causas de denegación de las decisiones extranjeras.

\section{EI derecho de defensa y la nulidad de actuaciones}

18. El motivo fundamental que alega el apelante es la vulneración del derecho de defensa. Entendemos que la indefensión puede plantearse porque se referiría a un acto procesal y no al fondo debatido. El AAP entiende que se da por cumplido este fundamental requisito: "No hay tampoco infracción del derecho de defensa (art. 46.1 b) porque el recurrente participó y asintió a la conciliación en el país de origen.".

Pero de lo que se trata es de si existe obligación de dar traslado de la petición de exequatur a la parte contraria, o no, en este procedimiento que perdió la naturaleza de acuerdo, y ello ha de hacerse en el marco de este y no extrayendo conocimientos que pudiera tener, o no, aquélla. El derecho a un juicio justo requiere obrar con toda cautela y diligencia y esta no se dará sin el trámite obligado.

Una cosa es el conjunto de causas de denegación previstas en el artículo $46^{15}$ y otra distinta es el procedimiento ${ }^{16}$.

\footnotetext{
${ }^{14}$ El Auto se refiere al "Juicio 17203201710847 ".

${ }^{15}$ En concreto, el artículo 46 b) "Cuando la resolución se hubiera dictado con manifiesta infracción de los derechos de defensa de cualquiera de las partes. Si la resolución se hubiera dictado en rebeldía, se entiende que concurre una manifiesta infracción de los derechos de defensa si no se entregó al demandado cédula de emplazamiento o documento equivalente de forma regular y con tiempo suficiente para que pudiera defenderse.".

${ }^{16}$ En particular, el artículo 54. 5. "La demanda y documentos presentados serán examinados por el secretario judicial, que dictará decreto admitiendo la misma y dando traslado de ella a la parte demandada para que se oponga en el plazo de treinta días. El demandado podrá acompañar a su escrito de oposición los documentos, entre otros, que permitan impugnar la autenticidad de la resolución extranjera, la corrección del emplazamiento al demandado, la firmeza y fuerza ejecutiva de la resolución extranjera.".
} 
Entendemos así, que se debió dar traslado al demandado a fin de evitar la consiguiente vulneración del derecho de defensa.

19. Si consideramos que se trata de una transacción judicial, no parece que el trámite de traslado debiera ser causa para invocar una nulidad de actuaciones. Ahora bien, si no se considera así, a tenor de lo dispuesto en la LCLI, sí lo sería, como alega el apelante y a lo que no se opone el Ministerio Fiscal.

20. Los artículos de la Ley Orgánica del Poder Judicial regulan la "nulidad los actos judiciales" en los artículos 238 a 243 (Título III del Libro III. Además, la Ley de Enjuiciamiento Civil (LEC) de 2000, en los artículos 225 a 231 (Capítulo IX del Título V del Libro I).

El artículo 238 dice, en su apartado $3^{\circ}$, que serán nulos (de pleno derecho) los actos procesales: "Cuando se prescinda de normas esenciales del procedimiento, siempre que, por esa causa, haya podido producirse indefensión". Y en igual sentido, el artículo 225 apartado $3^{\circ}$ : "Cuando se prescinda de normas esenciales del procedimiento, siempre que, por esa causa, haya podido producirse indefensión.”.

\section{Observaciones finales}

21. Entendemos, en definitiva, que: 1) acertando la decisión de la AP aplicando en defecto de convenio entre Ecuador y España y siendo inaplicable al supuesto del Derecho de la UE, la LCJI, sin embargo, 2) tratándose de un procedimiento en el que si bien, como hemos señalado, se llegó en un primer momento a un acuerdo, el mismo devino contencioso tal y como se demuestra con las actuaciones que el AAP recoge, con lo cual, 3) se debió proceder, tal y como ordena la norma española, a dar traslado de la solicitud de exequátur al demandado, por lo que en consecuencia, 4) existe nulidad de actuaciones al haberse producido indefensión por no haber atendido a una norma capital del proceso.

La contradicción entre las partes es necesaria para observar, de forma escrupulosa y debida, el principio consagrado en nuestra Constitución en su artículo 24 y que es -como no podía ser de otra forma- retomado en los ordenamientos internos, regionales o internacionales, como un derecho que forma parte de la legítima defensa, del derecho a un juicio justo. Si se vulnera este derecho decae el deber de justicia que ha de impregnar al derecho.

No podemos olvidar, como acertadamente afirman Calvo Caravaca y Carrascosa González, que la "LCJI se muestra muy garantista y supera en su afán de protección de los derechos de defensa de las partes, al Derecho de la UE” y “al de su norma modelo", refiriéndose al Convenio de Nueva York de 1958. ${ }^{17}$.

${ }^{17}$ a.L. calvo Caravaca J. carrascosa González, cit. p. 789. 